\title{
Differentiation of mouse embryonic stem cells and their hybrids during embryoid body formation
}

\author{
Josane Mittmann ${ }^{1}$, Irina Kerkis ${ }^{2}$, Cinthia Kawashima ${ }^{1}$, Marina Sukoyan ${ }^{2}$, Enrico Santos ${ }^{1}$ \\ and Alexandre Kerkis ${ }^{2}$ \\ ${ }^{1}$ Centro de Biociências e Biotecnologia, Universidade Estadual Norte Fluminense, Campos, RJ, Brazil. \\ ${ }^{2}$ Departamento de Biologia, Instituto de Biociências, Universidade de São Paulo, São Paulo, SP, Brazil.
}

\begin{abstract}
We studied the karyotypes of three hybrid clones of mouse embryonic stem cells and murine splenocytes (two having near diploid and one having near tetraploid chromosome numbers) and the characteristics of their differentiation during the formation of embryoid bodies. The $X$ chromosome originating from embryonic stem cells may be lost in hybrids with a near diploid chromosome number and reprogramming of the "somatic" $X$ may occur. The morphological data we obtained using light and electron microscopy revealed a correlation between the karyotype constitution of hybrid cells and their differentiation during the formation of embryoid bodies. At the beginning of development, the embryoid bodies derived from hybrid cells already showed an advanced degree of differentiation. The production of significant quantities of cartilage was typical for hybrid cells with near tetraploid chromosome numbers. The hybrid cells showed restricted pluripotent capacity and were already committed when they started to differentiate into embryoid bodies.
\end{abstract}

Key words: mouse ES-somatic cell hybrids, karyotype, pluriopotency, differentiation, embryoid bodies.

Received: May 2, 2000; accepted: July 3, 2000.

\section{Introduction}

Hybrids between pluripotent cells such as murine embryonic carcinoma cells (EC) and somatic cells (fibroblasts, splenocytes, lymphocytes etc.) can be used to study the differentiation of hybrid cells. Chromosome sets in hybrid cells can influence phenotype and differentiation capacity, giving new characteristics to the cells (Kerkis and Zhdanova, 1992; Takagi, 1997). Hybrids of EC cells with differentiated somatic cells have the phenotype of EC pluripotent cells and are able to differentiate into various tissues, derived from embryonic germ layers, and express some embryonic antigens (Miller and Ruddle, 1976; 1977; Litwack, and Croce, 1979; Andrews and Goodfellow, 1980; Rousset et al., 1983; Takagi et al., 1983; van der Kamp et al., 1984; Subramanian, 1989).

The pluripotency of cells has been evaluated by subcutaneous injection into syngeneic mice, resulting in the formation of teratocarcinomas. During differentiation not all hybrid clones produce the same pattern of cellular diversity (Miller and Ruddle, 1976). The restriction of the pluripotency of some hybrid clones may depend on their

Send correspondence to Alexandre Kerkis. Departamento de Biologia, IBUSP, C.P. 11461, 05422-970 São Paulo, SP, Brazil. E-mail: akerkis@usp.br. karyotype, but using an animal model it is difficult to determine the influence of karyotype because the differentiation of cells occurs under the developmental control of the parental organism.

Alternatively, the pluripotency of the cells can be examined by their capacity to form embryoid bodies (Ebs), which have similar characteristics to the initial stages of embryo development. This model has been shown to be useful in studies of cell differentiation (for reviews see: Pedersen, 1994; Keller, 1995). Such cells permit the study of the differentiation of pluripotent cells in vitro without the developmental influence of the animal environment. Under standardized culture conditions the observed differentiation can be attributed to the pluripotent cell genome.

Mouse embryonic stem cells (ES) are another type of pluripotent cell, which can be obtained from the inner cell mass of a normal embryo (Martin, 1981; Evans and Kaufman, 1981). Embryonic stem cells have been fused with differentiated mouse somatic cells (Matveeva et al., 1996) and human microcells (Tomizuka et al., 1997). The resulting hybrids had pluripotent characteristics in culture and could be used for the construction of transgenic (Tomizuka et al., 1997) and chimeric animals (Matveeva et al., 1998). Such hybrid cells can serve as a model for the 
study of the putative influence of the supplemental somatic chromosomes and other factors on differentiation.

In the study presented in this paper we used three mouse hybrid clones obtained by fusion of embryonic stem cells with splenocytes. We examined the karyotypes of these clones and investigated the influence of the karyotypes on the differentiation of these cells through the formation of embryonic bodies.

\section{Materials and Methods}

\section{Embryonic stem cells and their hybrids}

HM-1 cells, deficient in hypoxanthine phosphoribosyl transferase (HPRT), were derived from HPRT-deficient strain 129 mice (Magin et al., 1992) and characterized as highly pluripotent (Magin et al., 1992; Selfridge et al. 1992). The HESS-1, HESS-2 and HESS-3 hybrid cells were isolated by the fusion of HM-1 cells with murine splenocytes of $\mathrm{DD} / \mathrm{c}$ female, and characterized as pluripotents and HPRT positive by Matveeva et al. $(1996,1998)$.

We maintained the HM-1, HESS-1, HESS-2, HESS-3 cells in an undifferentiated state using a feeder layer of murine embryonic fibroblasts inactivated by mitomycin $\mathrm{C}(10 \mu \mathrm{g} / \mathrm{mL}$ for $3 \mathrm{~h})$. For cell cultivation without a feeder layer, the medium described below was supplemented with $10^{3}$ units $/ \mathrm{mL}$ of murine leukemia inhibitory factor (mLIF, Sigma) and Petri dishes were previously treated with an aqueous solution of $0.1 \%$ gelatin.

The HM-1 and hybrid cells were cultivated in the alpha-modification of Eagle's medium ( $\alpha$ MEM, Sigma) supplemented with $3.5 \mathrm{~g} / \mathrm{L} \mathrm{D}(+)$-glucose (Sigma), 10\% (v/v) bovine fetal serum, $10^{-4} \mathrm{M} \beta$-mercaptoethanol, $50 \mathrm{U} / \mathrm{mL}$ penicillin and $50 \mu \mathrm{g} / \mathrm{mL}$ streptomycin. For hybrid cell cultivation $\alpha$ MEM was supplemented with $100 \mu \mathrm{M}$ hypoxanthine, $0.4 \mu \mathrm{M}$ aminopterin and $16 \mu \mathrm{M}$ thymidine (HAT, Gibco), and the cells were passaged every 3 days onto a fresh feeder layer. Cultures were maintained in a humid atmosphere containing $5 \% \mathrm{CO}_{2}$ at $37^{\circ} \mathrm{C}$.

For selection by 6-thioguanine, hybrid cells were plated in complete Eagles culture medium supplemented with $10^{3}$ units $/ \mathrm{mL}$ mLIF and $30 \mu \mathrm{g} / \mathrm{mL}$ 6-thioguanine on gelatinized $60 \mathrm{~mm}$ dishes (3600-3800 cells/dish), the colonies being examined after 8-10 days of cultivation.

\section{Embryoid body formation}

Embryoid bodies were obtained by cultivation of ES cells and their hybrids in suspension according to the protocol of Robertson (1987), using the same medium as that for undifferentiated cell culture, excluding mLIF and $\beta$-mercaptoethanol. Embryonic stem and hybrid cells were trypsinized and the suspension left in a culture flask in the $\mathrm{CO}_{2}$ incubator for $15 \mathrm{~min}$ to eliminate fibroblasts, after which the suspension was transferred to another flask and incubated overnight. On the following day cell aggregates were separated by shaking, re-suspended in culture medium and placed into bacteriological dishes, the medium being changed every 2-3 days.

\section{Alkaline phosphatase activity and cytogenetic analysis}

The hybrid and HM-1 cells growing on microscope slides with feeder cells were washed in 0.1 M PBS, pH 7.4 and fixed with $4 \%$ paraformaldehyde in PBS for 15 min. Standard histochemical techniques were used for the detection of alkaline phosphatase (AP) activity in the undifferentiated cells (Talbot et al., 1993).

For chromosome studies all cell lines were treated according to Hogan et al., 1994 and trypsin-Giemsa banding were obtained by the method of Seabright 1971. At least 250 different metaphases from each line were analyzed. Embryoid bodies were pre-treated with type III collagenase (Sigma).

\section{Optical and electron microscopy studies of EBs}

For optical microscopy embryoid bodies were fixed with $4 \%$ paraformaldehyde in $0.2 \mathrm{M}$ PBS for one hour at room temperature and maintained at $4{ }^{\circ} \mathrm{C}$ overnight before being embedded in paraffin and cut into 3-5 $\mu$ sections which were then Gomori stained (Behmer et al., 1976).

For electron microscopy the embryoid bodies were fixed in a mixture of $2.5 \%$ gluteraldehyde, $4 \%$ paraformaldehyde and $0.1 \mathrm{mM} \mathrm{CaCl}_{2}$ in $0.1 \mathrm{M}$ cacodylate buffer $(\mathrm{pH}$ 7.4) for $1 \mathrm{~h}$. Post-fixation was performed with $1 \%$ osmium tetroxide $\left(\mathrm{OsO}_{4}\right)$ in the same buffer for $30 \mathrm{~min}$, followed by embedding in Epon 812. After polymerization, sections were cut with a Reichert's Ultracut ultramicrotome using a diamond knife. The sections were treated with an aqueous solution of uranyl acetate and lead citrate to enhance contrast (Reynolds, 1963). The samples were analyzed using a Zeiss IN 900 electron microscope.

\section{Results}

\section{Morphologic pattern of the hybrid cell cultures}

Colonies formed by the HESS-2 and HESS-3 hybrid cells were similar to HM-1 cells, being composed of many small, round and juxtaposed cells. HESS-1 cells were less similar to the parental HM-1 line and their colonies formed on a fibroblast layer were heterogeneous and consisted of large, round cells. On the top of the colony there were some small cells similar to HM-1 cells. 


\section{Cytogenetic analysis}

HM-1 cells were stable and had a normal diploid chromosome number of $2 \mathrm{n}=40(38 \mathrm{~A}+\mathrm{XY})$, without any aneuploidy or structural alterations up to 30 passages in culture.

Analysis of HESS-1 cells after 25 passages showed that this hybrid was heterogeneous, with chromosome numbers from $2 n=40$ up to 80 , with a modal number of 71 chromosomes. Different patterns of sexual chromosomes were observed, the XXXY karyotype being frequently seen and the XXY karyotype rarely observed. The karyotypes with 41-43 chromosomes included trisomies for chromosomes 1, 11, 14 and 16 .

Karyotype analysis of HESS- 2 cells after 38 passages showed a predominance of cells with 42 chromosomes. Almost all metaphases had a pair of XY sex chromosomes. Among 47 metaphase spreads only seven (15\%) had two X chromosomes, while $50 \%$ showed a chromosome fragment, probably derived from chromosome 5. Trisomy of chromosomes 1, 11, 12 or 16 was observed, Figure 1 showing the XY karyotype with trisomy 11 and the chromosome fragment.

The modal chromosome number of HESS-3 cells after 39 passages was 41 , including only one $\mathrm{X}$ chromosome. Cells with XXY or XX sex chromosomes were not observed, although trisomies for chromosomes $1,11,15$ or 17 were detected (Figure 2).

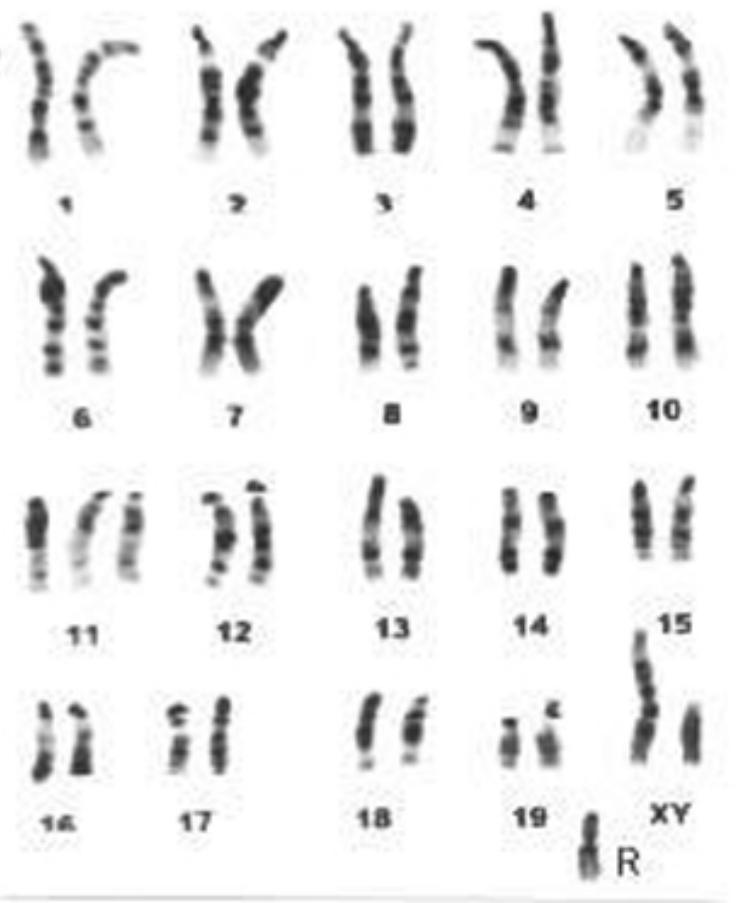

Figure 1 - GTG-banded karyotype of a HESS-2 cell with trisomy of chromosome 11 and a structural rearrangement (R) (Passage 38).
Cytogenetic analysis of embryoid bodies showed that the karyotypes of these bodies on the $7^{\text {th }}$ day of their formation had almost the same modal number as the hybrid clones in cell culture (Table 1).

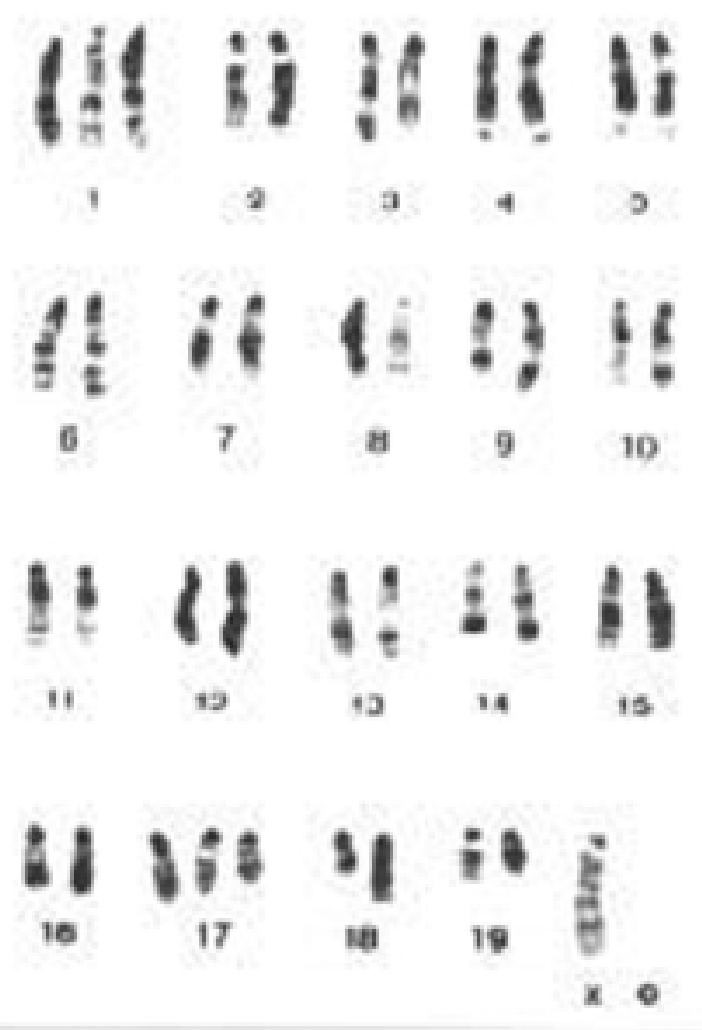

Figure 2 - GTG-banded karyotype of a HESS-3 cell with trisomy of chromosome 1 and 17 (Passage 39).

Table I - Frequency of different chromosome numbers in 7-day embryoid bodies derived from HESS-1, HESS-2 and HESS-3 hybrid cells.

\begin{tabular}{lccc}
\hline \multirow{2}{*}{$\begin{array}{l}\text { Chromosome } \\
\text { number }\end{array}$} & \multicolumn{3}{c}{ Number of metaphases analyzed } \\
\cline { 2 - 4 } & HESS-1 & HESS-2 & HESS-3 \\
\hline 40 & - & $46(23.0)^{1}$ & $36(18.0)^{1}$ \\
41 & $2(4.2)^{1}$ & $101(50.5)$ & $81(40.5)$ \\
42 & $5(10.4)$ & $24(12.0)$ & $46(23.0)$ \\
43 & - & $29(14.5)$ & $37(18.5)$ \\
64 & $1(2.1)$ & - & - \\
68 & $1(2.1)$ & - & - \\
69 & $6(12,5)$ & - & - \\
70 & $2(4.2)$ & - & - \\
71 & $4(8.3)$ & - & - \\
72 & $11(22.9)$ & - & - \\
73 & $6(12.5)$ & - & - \\
74 & $6(12.5)$ & - & - \\
75 & $3(6.2)$ & - & - \\
77 & $1(2.1)$ & - &
\end{tabular}

${ }^{1}$ Percentage in parenthesis. 


\section{Origin of the $\mathrm{X}$ chromosome in the hybrid cell}

Most HESS- 2 and HESS- 3 cells had only one X chromosome. To investigate the origin of this chromosome cells were treated with 6-thioguanine, a chemical which allows the selection of HPRT-deficient cells (Verma and Babu, 1995). HESS-3 cells were unable to grow in the presence of 6-thioguanine but were able to grow in the selective HAT medium (Table 2). This was a predictable result, since before selection with 6-thioguanine the HESS-3 cells could not have lost the 'somatic' $\mathrm{X}$ chromosome due to the pre-cultivation in HAT medium. Therefore the frequency of cells with only one chromosome X of 'embryonic origin' in the HESS-3 hybrid cells was less than $2.6 \times 10^{-4}$.

When the HESS- 2 cells were repeatedly cultivated in the presence of HAT approximately $15 \%$ of the cells had two $\mathrm{X}$ chromosomes, as described above. It is conceivable that in the absence of selective pressure these cells lost one of their $\mathrm{X}$ chromosomes, i.e. the 'somatic origin' $\mathrm{X}$ chromosome could be preferentially lost, as the chromosome of the more differentiated partner of cell fusion (Ringertz and Savage, 1976). We cultivated HESS-2 cells for 27 days (11 passages) without HAT and then subjected them to selection with 6-thioguanine (Table 2). None of the colonies of the hybrid cells grew in the culture medium with 6-thioguanine (a frequency below $2.7 \times 10^{-4}$ ), whereas HAT-resistant colonies had a frequency of about $3 \times 10^{-2}$. These results show that in the absence of selective pressure (during about 50 cell divisions) the $\mathrm{X}$ chromosome of somatic origin $\left(\mathrm{HPRT}^{+}\right)$was not lost, instead the X chromosome originating from the ES cells $\left(\mathrm{HPRT}^{+}\right)$.

\section{Alkaline phosphatase (AP) activity}

Table 3 shows the percentage of AP positive cells in the HM- 1 and hybrid cells. The largest numbers of AP positive cells (about 94\%, Figure 3a) were found in HM-1 cells but the HESS- 3 line also had a large percentage (higher than $90 \%$ ) of AP positive cells. HESS-2 had a smaller number of AP positive cells (about $56 \%$, Figure $3 \mathrm{~b}$ ) and the HESS-1 line the smallest number of AP positive cells (about 14\%). In general, among the heterogeneous cells of the HESS-1 line only small cells were AP positive, whereas larger cells were weakly stained (Figure 3c).
Table III - Percentage of alkaline phosphatase positive cells in undifferentiated cultures of HM-1 cells and their hybrids.

\begin{tabular}{lcc}
\hline Cell lines & Total number of cells & Number of AP- positive cells \\
\hline HM-1 & 1106 & $950(94.4)^{1}$ \\
HESS-1 & 11484 & $1597(13.9)$ \\
HESS-2 & 2320 & $1305(56.3)$ \\
\hline
\end{tabular}

${ }^{1}$ Percentage in parenthesis.

\section{Optical and electron microscopy of embryoid bodies}

Comparative analysis of sections of EBs revealed a variety of differentiated cells in the hybrids and the HM-1 line. In the EBs originating from HM-1 cells, endodermal, cartilage-like and blood-like cells were marked positively at day 9 (Figure 4a). In EBs derived from HESS-2 and HESS-3 lines the formation of a large amount of cartilage matrix was observed in different parts of the EBs sections (Figure $4 \mathrm{~b}$ ). The inner part of the EBs showed a larger amount of cartilage matrix in sections obtained from HESS- 1 cells (Figure 4c). On the periphery of the bodies a layer of the endodermal cells and islands of blood cells were also observed (Figures $4 b$ and $4 c$ ).

Electron microscopy of the EBs revealed distinctive differences in the EBs formed by hybrids and by HM-1 cells. At day 3, EBs derived from HM-1 had an outer layer of endodermal cells. These cells were at the beginning of their differentiation since they possessed few microvilli and few cytoplasmic organelles (Figure 5a). The central part of the EBs consisted of round undifferentiated cells with a large nuclei and cytoplasm with a small number of organelles (Figure 5b). On day 9, the outer layer of HM-1 derived EBs showed epithelium-like cells with numerous microvilli. These cells had junction structures of the desmosome type and Reichert's membrane was well developed and the cystic cavity could be seen. In the inner part of the bodies muscular-like cells, adipose-like and haematopoietic stem-like cells at various stages of differentiation (Figure 5c,g) were also found. On day 9, the HM-1 derived EBs showed the characteristic rhythmic contractions of heart muscle cells.

On day 3, EBs derived from hybrids presented an advanced degree of differentiation. Embryoid bodies derived from HESS-2 and HESS-3 lines had an endodermal layer

Table II - Comparison of plating efficiency of the hybrid cells in the presence of 6-thioguanine and HAT (100 $\mu \mathrm{M}$ hypoxanthine, $0.4 \mu \mathrm{M}$ aminopterin and $16 \mu \mathrm{M}$ thymidine).

\begin{tabular}{lcccc}
\hline Hybrid & Passage number & Number of cells & 6-thioguanine resistant colonies & HAT-resistant colonies \\
\hline HESS-3 & 39 & 3800 & $0\left(2.6 \times 10^{-4}\right)^{1}$ & $52\left(1.4 \times 10^{-2}\right)^{1}$ \\
HESS-2* & 47 & 3600 & $0\left(2.8 \times 10^{-4}\right)$ & $115\left(3.2 \times 10^{-2}\right)$ \\
\hline
\end{tabular}

${ }^{1}$ Frequency.

*These cells were pre-cultivated in the absence of HAT for 27 days (11 passages). 

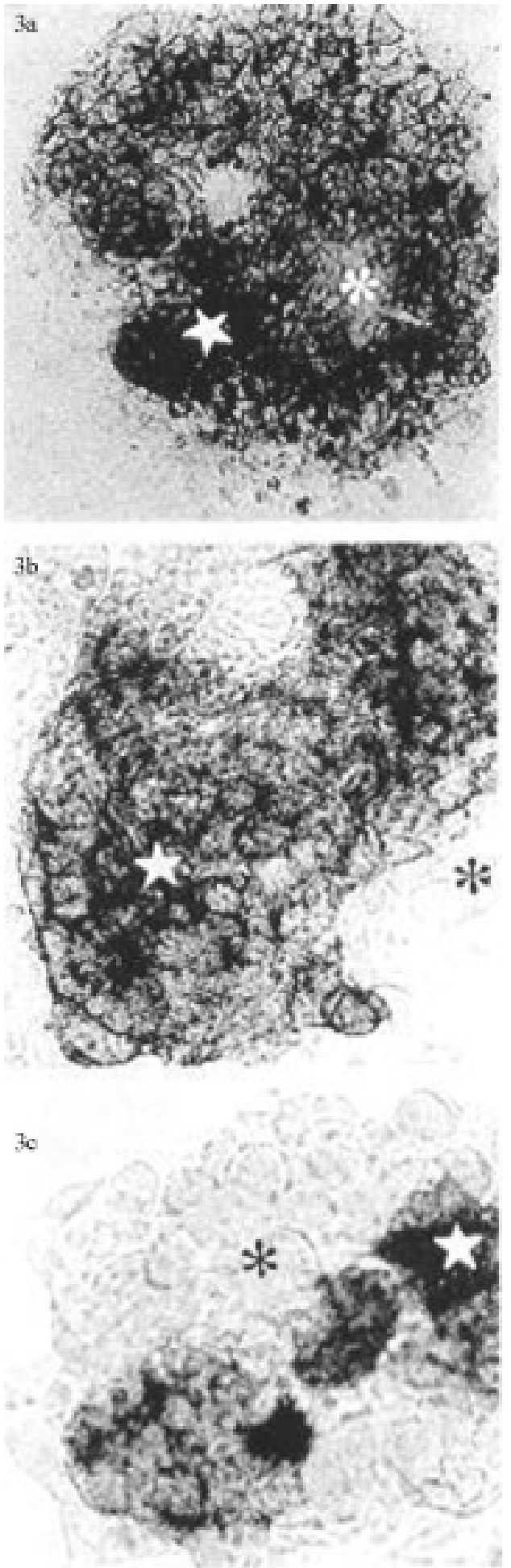

Figure 3 - Localization of AP activity in: HM-1 (3a), HESS-2 (3b) and HESS-1 (3c) cells during cultivation on a feeder layer. AP-positive ( and AP-negative cells $(*)$. All at $800 x$ magnification.

formed by cells already possessing multiple microvilli and an organelle-enriched cytoplasm. The start of Reichert's membrane formation was initiate and cells resembling embryonic fibroblasts could be seen under this membrane (Figure 6a). The central part of individual EBs contained

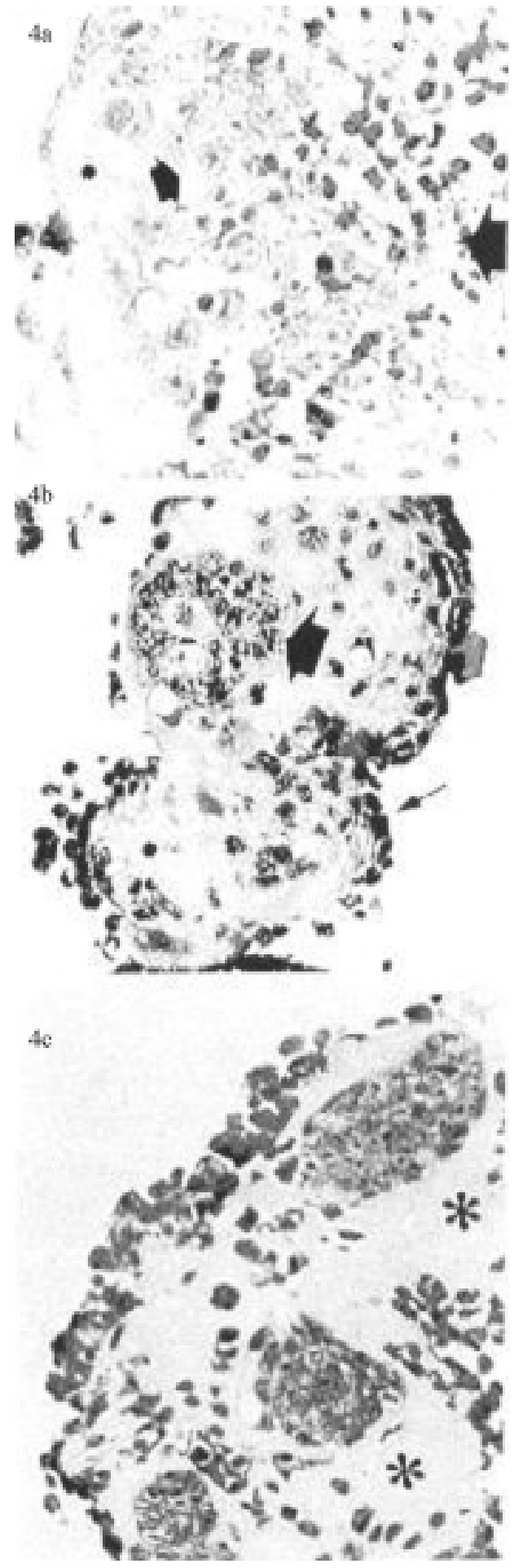

Figure 4 - Light microscopy of Gomori stained sections of nine-day old embryoid bodies derived from the hybrids and HM-1 cells: HM-1 (4a, 1500x). HESS-2 (4b) and HESS-1 (4c) both at 800x magnification. Cartilage matrix $(*)$, chondroblast-like cells $(-)$, outer layer of endodermal cells $(\uparrow)$ and blood cell islands $(\rightarrow)$

morphologically undifferentiated cells. At a comparable stage of cultivation, EBs derived from HESS-1 hybrid cells were not very compact and the large spherical cells on their outer surface probably had near tetraploid chromosome 

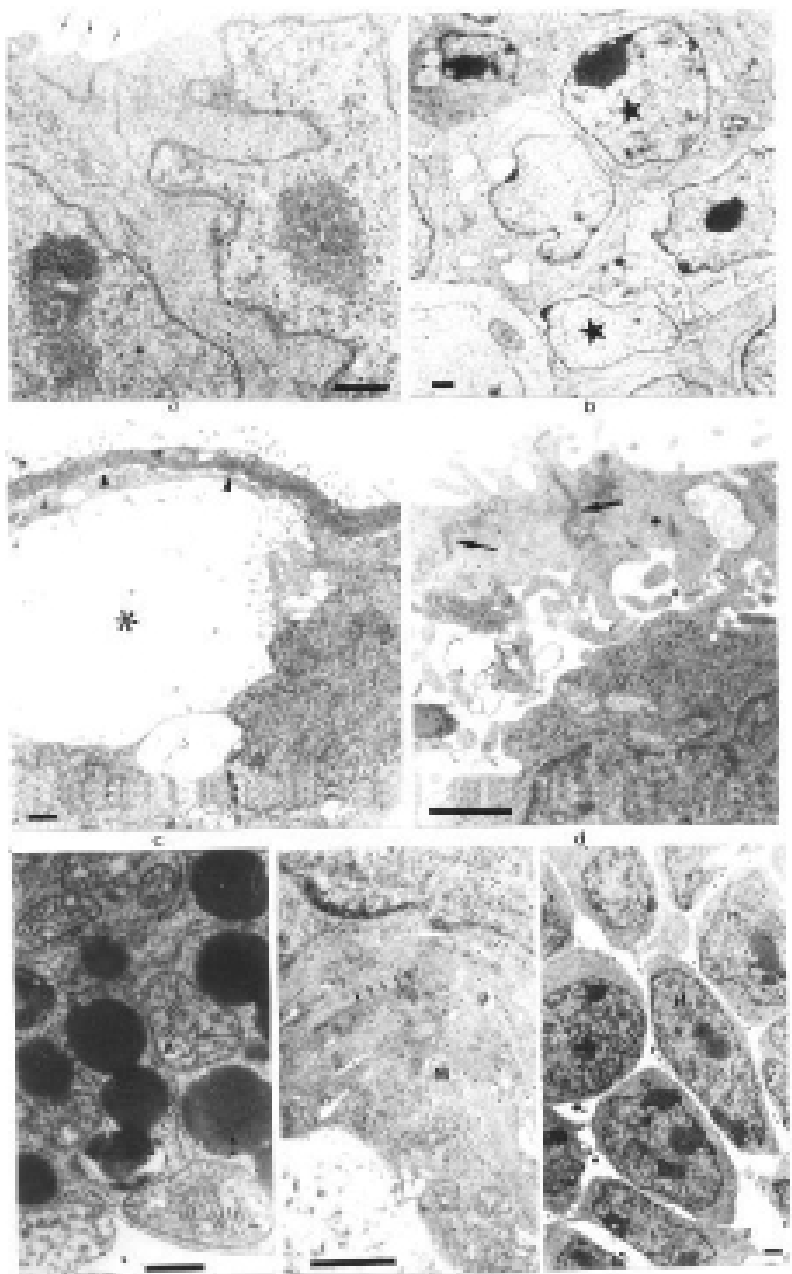

Figure 5 - Electron micrographs showing parts of HM -1 cell derived embryoid bodies (EBs). A 3-day embryoid body (EB) showing the appearance of the outer layer of endodermal cells with a few microvilli $(\uparrow)$ and cytoplasm with only a few organelles (5a, 12000x). The same EB showing the central part formed by undifferentiated cells $(\star)(5 \mathrm{~b}, 4300 \mathrm{x})$. Figures $5 \mathrm{c}$ to $5 \mathrm{~g}$ all show 9-day EBs: Reichert's membrane $(\rightarrow)$ and the cystic cavity $(*)(5 \mathrm{c}, 6300 \mathrm{x})$; endodermal cells with a large number of microvilli $(\uparrow)$ and junction structures $(\bullet)(5 \mathrm{~d}, 17600 \mathrm{X})$; different types of cells can be seen in the inner part of EBs, e.g. adipose-like cells (A) (5e 12000x), muscle-like cells $(\mathrm{M})$ and myofibers $(\uparrow)(5 \mathrm{f}, 1800 \mathrm{x})$, haematopoietic stem-like cells $(\mathrm{H})(5 \mathrm{~g}, 3300 \mathrm{x}) . \mathrm{Bar}=1 \mu \mathrm{m}$.

numbers. These cells had a cytoplasm rich in organelles, mainly granular endoplasmatic reticulum (Figure 6b).

From day 9 to 18 , the outer layer of endodermal cells had a greater number of microvilli and their cytoplasms were filled with endoplasmatic reticulum. The cystic cavities were well formed (Figure 6c) and areas resembling blood cell islands could be seen at the center of the EBs (Figure 6d). An important characteristic of differentiated hybrid cells was the production of a large number of polysaccharide granules and a lot of extracellular collagen secreted by chondroblasts or fibroblast-like cells (Figure 6e and 6f).

Embryoid bodies derived from hybrids lacked cells of the muscular type. To investigate whether these cells had

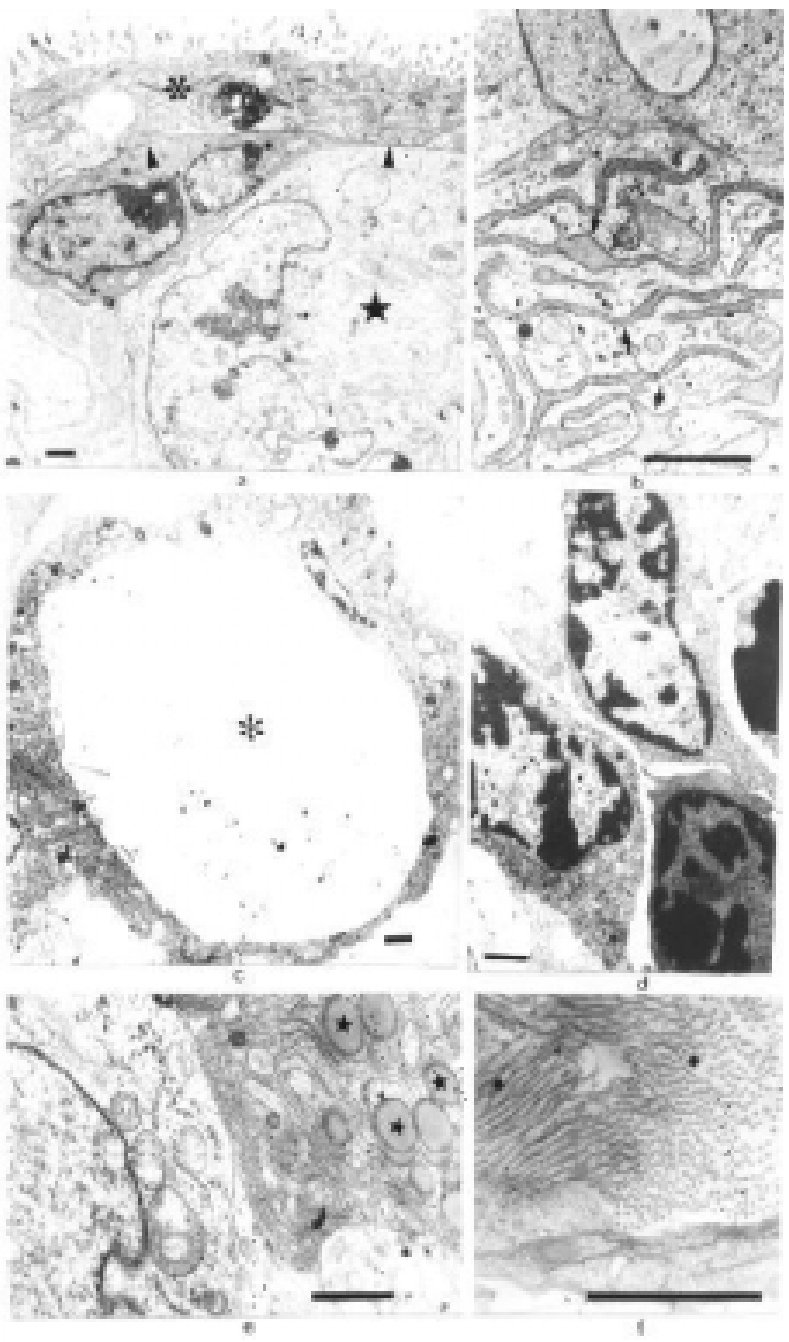

Figure 6 - Electron micrographs showing parts of HESS-1, HESS-2 and HESS-3 derived embryoid bodies (EBs). An advanced degree of differentiation can be seen in three-day EBs as follows: HESS-2-derived embryoid body (EB) showing Riechert's membrane ( $\bullet$ ) which separates an endodermal layer $(*)$ formed by cells with multiple microvilli $(\uparrow)$ and the cytoplasm enriched with organelles, the asterisk marks cells resembling embryonic fibroblasts (6a, 5000x); HESS-1-derived EB showing a fragment of the granular endoplasmatic reticulum $(\uparrow)$ typical of fibroblasts (6b, 19000x). Nine-day EBs: HESS-1-derived EB showing a well formed cystic cavity $(*)$ (6c 5200x); center of a HESS-2-derived EB showing areas resembling blood cell islands (6d, 8700x); HESS-3-derived EB showing fibroblast-like cells with granular endoplasmatic reticulum and polysaccharide granules $(\star)(6 e, 15000 x)$; HESS-2-derived EB with a large amount of collagen produced by condroblasts $(-)$ (6f, 32000x). $\operatorname{Bar}=1 \mu \mathrm{m}$.

the capacity to differentiate into muscle cell, we allowed the EBs to develop up to 30 days. Only a few HESS-2 derived EBs presented muscular contractions on the $10^{\text {th }}$ to $15^{\text {th }}$ day, the other hybrids not showing such contractions.

\section{Discussion}

We attempted to evaluate the influence of near diploid and near tetraploid karyotypes on the in vitro differentiation of hybrid cells obtained by fusion of somatic and 
embryonic genomes. If karyotype is influential, its effects would appear at the initial stages of embryo formation which is very sensitive and important for normal development. For this reason we chose Ebs as a model of early development, a choice which permitted us to study differentiation without any influence of the parental organism.

It is noteworthy that the intraspecific hybrids between the pluripotent and somatic cells usually have a near tetraploid chromosome number (Takagi, 1997). The hybrid cells used in our study were near diploid (HESS-2 and HESS-3) and near tetraploid (HESS-1) and our chromosome analysis showed different trisomies, trisomies of chromosomes 1 and 11 being found in near diploid hybrids. These trisomies are probably typical of pluripotent cells, and have previously been described in the MESC embryonic cell line (Crolla et al., 1990) and in embryonic carcinoma cells (McBurney and Rogers, 1982).

We found that the sex chromosome constitution in the HESS-2 line was predominantly XY, while in the HESS-3 line it was XO. This observation was unexpected since in the hybrid cells two X chromosomes should stay together because one $\mathrm{X}$ had the HPRT gene that was maintained by cultivation in HAT, while the other X belonged to the pluripotent embryonic cells. Indeed, it has been demonstrated by Ringertz and Savage (1976) that hybrids lose the chromosomes originating from differentiated, more slowly dividing, cells. Thus our results raised the question of the origin of the $\mathrm{X}$ chromosome in the hybrid cells, and to answer this question we used 6-thioguanine selection. In HESS- 2 and HESS- 3 lines, the segregated $X$ chromosome was demonstrated to be of embryonic origin. Therefore, the segregation of the $\mathrm{X}$ chromosome of the more differentiated fusion partner during non-selective cultivation is not a rule in these hybrids.

During embryoid body formation the selection of cells with a diploid $(2 n=40)$ karyotype is possible, but we did not detect selection for cells with a given chromosome number since the karyotypes of 7 day hybrid-derived embryoid bodies (EBs) maintained the same modal chromosome number as the cells in monolayer culture.

In culture, HESS-1, HESS-2 and HESS-3 lines had, like other hybrids (q.v. review in Takagi, 1997), the phenotype of pluripotent cells, the AP-reaction being considered as a marker of pluripotency (Resnick et al., 1992; Talbot et al., 1993). We found the highest number of AP-positive cells in the HESS-3 and HESS- 2 cell lines, which most resembled the parental HM-1 line in morphological characteristics. The HESS-1 line was heterogeneous for the AP-reaction, HESS-1 AP-positive cells having near diploid chromosome numbers and AP-negative cells near tetraploid chromosome numbers.

In our experiments, hybrids showed the capacity to form EBs in vitro, even at late passages. The EBs formed by the hybrid cells could be considered as complex as those derived from the HM-1 line and the cystic-type EBs formed by pluripotent cells (Martin and Evans, 1975; van der Kamp et al., 1984; Doetschman et al., 1985; Pease et al., 1990).

The formation of blood cell islands, similar to the yolk sac, has been described in EBs derived from different ES cell lines (Doetschman et al., 1985; Hollands, 1988; Nichols et al., 1990; Chen, 1992; Bautch et al., 1996). We also observed haematopoietic-like cells in the EBs derived from hybrids and HM-1 cells. The formation of these cell types was related to the presence of visceral endoderm-like cells which we detected using electron microscopy. These cells possessed microvilli on their surface, cytoplasmatic vesicles and gap junction-like structures. Bautch et al. (1996) observed the precursors of haematopoietic cells that were localized in the center of EBs, but they migrated to the periphery as soon as they became differentiated. Our electron microscopy and histochemical analyses revealed cells with a high cytoplasm:nucleus ratio in the central area of EBs formed by the hybrids. These cells may be considered haematopoietic-like precursors.

Cells resembling skeletal and smooth muscle were seen during differentiation of the HM-1 line. The presence of the mesodermal cells showed that EBs obtained from this line follow the typical embryoid body pattern of development (Doetschman et al., 1985; Nichols et al., 1990; Bautch et al., 1996). The hybrid cells did not show this type of differentiation in EBs at the initial stages of development, suggesting restricted pluripotency.

Cells of ectodermal origin (e.g. nerve cells) were not identified in EBs derived from HM-1 cells and hybrids. The absence of nerve cells might be explained because cell differentiation took place in suspension, while nerve cells require a solid substrate and specific inductors for differentiation (Bain et al., 1995; Fraichard et al., 1995).

Studies of the influence of the karyotype on ES cell pluripotency have demonstrated that the normal karyotype may be a prerequisite for the efficient contribution of these cells to the germ line in transgenic and chimeric animals and for their ability to differentiate in vitro into a wide spectrum of cell types (Papaioannou et al., 1978; McBurney, Rogers, 1982; Pease et al., 1990; Bronson et al., 1995; Liu et al., 1997; Suzuki et al., 1997). Our data shows that the 'embryonic' X chromosome may be lost in pluripotent hybrids, but reprogramming of the 'somatic' $\mathrm{X}$ chromosome may still occur, thus allowing restricted pluripotency. Near diploid and near tetraploid hybrids did not differ as to their pluripotency, but appeared, however, to be restricted as compared to normal ES cells.

\section{Acknowledgments}

We are thank Dr. O. Serov for the HM-1 and hybrid cells, Dr. Ekkehard Hansen for helpful suggestions and Ms M.A. da Silva Carvalho Dutra for taking the photographs. Our special gratitude to Dr. Antonio Cordeiro for his 
contribution to our laboratory. This work was supported by FENORTE and CAPES, Brazil.

\section{References}

Andrews PW, Goodfellow PN (1980) Antigen expression by somatic cell hybrids of a murine embryonal carcinoma cell with thymocytes and L cell. Somat Cell Genet 6:271-284.

Bain G, Kitchens D, Yao M, Huettner JE, Gottlieb DI (1995) Embryonic stem cells express neuronal properties in vitro. Dev Biol 168 (2):342-357.

Bautch VL, Standford WL, Rapoport R, Russel S, Byrum RS, Futch TA (1996) Blood island formation in attached cultures of murine embryonic stem cells. Dev Dyn 205:1-12.

Behmer OA, Tolosa EMC, Neto AGF (1976) Manual de técnicas para histologia normal e patológica. EDART- São Paulo, Livraria Editora da Universidade de São Paulo, 25p.

Bronson SK, Smithies O, Mascarello JT (1995) High incidence of $\mathrm{XXY}$ and XYY males among the offspring of female chimeras from embryonic stem cells. Proc Natl Acad Sci (USA), 92:3120-3123.

Chen U. (1992) Differentiation of mouse embryonic stem cells to lympho-hematopoietic lineages in vitro. Dev Immun 2:29-50.

Crolla JA, Brown D, Whittingham DG (1990) Spontaneous induction of an homologous Robertsonian translocation, $\mathrm{Rb}$ (11.11) in a murine embryonic stem cell line. Genet Res 55:107-110.

Doetschman T, Eistetter H, Katz M, Schmidt W, Kemler R (1985) The in vitro development of blastocyst-derived embryonic stem cell lines: formation of visceral yolk sac, blood islands and myocardium. J Embryol Exptl Morph 87:27-45.

Evans M, Kaufman M (1981) Establishment in culture of pluripotential cells from mouse embryos. Nature 292:154-156.

Fraichard A, Chassande O, Bilbaut G, Dehay C, Savatier P, Samarut J (1995) In vitro differentiation of embryonic stem cells into glial cells and functional neurons. J Cell Sci 108:3181-3188.

Hogan B, Beddington R, Costantini F, Lacy E (1994) Manipulating the Mouse Embryo: A Laboratory Manual. Cold Spring Harbor Laboratory Press, New York, 332p.

Hollands P (1988) Differentiation of embryonic haematopoietic stem cells from mouse blastocysts grown in vitro. Development 102:135-141.

Keller GM (1995) In vitro differentiation of embryonic stem cells. Current Opinion in Cell Biology 7:862-869.

Kerkis AYu, Zhdanova NS (1992) Formation and ultrastructure of somatic cell hybrids. Electron Microscopy Rev 33:1-24.

Litwack G, Croce CM (1979) Somatic cell hybrids between totipotent mouse teratocarcinoma and rat hepatoma cells. J Cell Physiol 101:1-8.

Liu X, Wu H, Loring J, Hormuzdi S, Disteche CM, Bornstein P, Jaenisch R (1997) Trisomy eight in ES cells is a common potential problem in gene targeting and interferes with germ line transmission. Dev Dyn 209:85-91.

Magin TM, McWhir J, Melton DW (1992) A new mouse embryonic stem cell line with good germ line contribution and gene targeting frequency. Nucl Acid Res 20:3795-3796.

Martin GR (1981) Isolation of a pluripotent cell line from early mouse embryos cultured in medium conditioned by terato- carcinoma stem cells. Proc Natl Acad Sci (USA) 78:7634-7638.

Martin GR, Evans MJ (1975) Differentiation of clonal lines of teratocarcinoma cells: formation of embryoid bodies in vitro. Proc Natl Acad Sci (USA) 72:1441-1445

Matveeva NM, Shilov AG, Bayborodin SI, Filimonenko VV, Rolinskaya IV, Serov OL (1996) Hybrids between mouse embryonic and somatic cells retain pluripotency. Proc Acad Sci (Russia) 349:129-132.

Matveeva NM, Shilov AG, Kaftanovskaya NM, Maximovsky LP, Zhelezova AI, Golubitsa AN, Bayborodin SI, Fokina MM, Serov OL (1998) In vitro and in vivo study of pluripotency in intraspecific hybrid cells obtained by fusion of murine embryonic stem cells with splenocytes. Mol Reprod Dev 50:128-138.

McBurney WM, Rogers BJ (1982) Isolation of male embryonal carcinoma cells and their chromosome replication patterns. Dev Biol 89:503-508.

Miller RA, Ruddle FH (1976) Pluripotent teratocarcinoma-thymus somatic cell hybrids. Cell 9:45-55.

Miller RA, Ruddle FH (1977) Teratocarcinoma x Friend erythroleukemia cell hybrids resemble their pluripotent embryonal carcinoma parent. Dev Biol 56:157-173.

Nichols J, Evans EP, Smith AG (1990) Establishment of germ-line-competent embryonic stem (ES) cells using differentiation inhibiting activity. Development 110:1341-1348.

Papaioannou VE, Gardner RL, McBurney WM, Babinet C, Evans MJ (1978) Participation of cultured teratocarcinoma cells in mouse embryogenesis. J Embryol Exp Morphol 44:93-104.

Pease S, Williams RL (1990) Formation of germ-line chimeras from embryonic stem cells maintained with recombinant leukemia inhibitory factor. Exp Cell Res 190:209-211.

Pedersen RA. (1994) Studies of in vitro differentiation with embryonic stem cells. Reprod Fertil Dev 6:543-552.

Resnik JL, Bixler LS, Cheng L, Donovan PJ (1992) Long-term proliferation of mouse primordial germ cells in culture. Nature 359:550-551.

Reynolds ES (1963) The use of lead citrate of high $\mathrm{pH}$ for electron opaque stain in electron microscopy. J Cell Biol 17:208.

Ringertz NR, Savage RE (1976) Cell hybrids. Acad. Press, New York, 417 pp.

Robertson EJ 1987 Embryo-derived stem cell lines. In: Robertson EJ, editor. Teratocarcinomas and embryonic stem cells. A practical approach. IRL Press, Oxfordm pp. 71-112.

Rousset J-P, Bucchi D, Jami J (1983) Hybrids between F9 nullipotent teratocarcinoma and thymus cells produce multi-differentiated tumors in mice. Dev Biol 96:331-336.

Seabright M (1971) A rapid banding technique for human chromosome. Lancet 2:971-972.

Selfridge J, Pow AM, McWhir J, Magin TM, Melton DW (1992) Gene targeting using a mouse HPRT mini/HPRT-deficient embryonic stem cell system: inactivation of the mouse ERCC-1 gene. Somat Cell Mol Genet 18: 325-336.

Subramanian V (1989) A malignant, stem cell-like somatic hybrid between a mouse teratocarcinoma and rat ascitic hepatoma is differentiation competent. Cell Differ Dev 27:197-214.

Suzuki H, Kamada N, Ueda O, Jishage K, Kurihara H, Terauchi Y, Azuma S, Kadowaki T, Kodoma T, Yazaki Y, Toyoda Y (1997) Germ-line contribution of embryonic stem cells in chimeric mice: influence of karyotype and in vitro differentiation ability. Exp Anim 46:17-23. 
Talbot NC, Rexrod CE, Pursel V, Powell AM (1993) Alcaline phosphatase staining of pig and sheep epiblast cells in culture. Mol Reprod Dev 36:139-147.

Takagi N, Yoshida MA, Sugawara O, Sasaki M (1983) Reversal of X-inactivation in female mouse somatic cells hybridized with murine teratocarcinoma stem cells in vitro. Cell 34:1053-1062.

Takagi N (1997) Mouse embryonal carcinoma cell - somatic hybrids as experimental tools for the study of cell differentiation and $\mathrm{X}$ chromosome activity. Cancer Genet Cytogenet 93:48-55
Tomizuka K, Yoshida H, Uejima H, Kudoh H, Sato K, Ohguma A, Hayasaka M, Honaoka K, Oshimura M, Ishida I (1997) Functional expression and germline transmission of a humane chromosome fragment in chimaeric mice. Nature Genetics 16:133-143.

Van der Kamp AW, Roza-de Jongh EJ, Houwen RH, Magrane GG, van Dongen JM, Evans MJ (1984) Developmental characteristics of somatic cell hybrids between totipotent mouse teratocarcinoma and rat intestinal villus cells. Exp Cell Res 154 (1):53-64.

Verma RS, Babu A (1995) Human chromosomes - Principles and techniques. McGraw-Hill, New York, 419 pp. 